\title{
Thermal NdE of FRP applied to civil structures
}

\author{
by E.Grinzato*, V.A.M. Luprano**, S. Marinetti*, P.G. Bison*, R. Trentin*, \\ A.Tundo** and A. Tati***
}

${ }^{*}$ CNR-ITC, c.so Stati Uniti,4 -35127 Padua, Italy

${ }^{* *}$ ENEA S.S. 7 Appia km 714 - 72100 Brindisi, Italy

${ }^{* * *}$ ENEA Casaccia - S.Maria di Galeria - Roma, Italy

\begin{abstract}
Different techniques have been used to detect and characterize delaminations between concrete and Fibre-Reinforced Polymers applied as reinforcement of civil structures. The main aim of this work is to develop a reliable and confident nondestructive testing procedure to characterize the location and size of delaminations.

Thermal modelling and experiments on concrete bonded with FRP and containing defects properly created at the interface are presented. The influence on the evaluation of defects of the heating, the kind of FRP and the finishing layer of the reinforcement are analysed.

Finally, a comparison between thermography and ultrasonic wave measurements will be carried out. The cross evaluation allows to analyse not only artificial defects but natural ones.
\end{abstract}

\section{Introduction}

Civil structures are often demanded to work for a very long period, during which a reinforcing of the structure can be necessary. The structural capability could require a strengthening mainly due to the aging or the use of substandard materials, a variation of the applied loads in respect to the design or a change of the building code, that implied a revision of the seismic resistance criteria.

In the last few years, one of the most promising strengthening/repairing techniques is based on the use of advanced composite materials for building a strong coating of concrete structures. In particular, the commonly used composites are Fibre-Reinforced Polymers (FRP), made up of a polymeric matrix, such as epoxy resin and high-strength fibres, as carbon, glass or aramid. The FRP reinforcement to be effective has to rely on the perfect adhesion between the FRP and the substrate, but composites are applied in situ in barely controlled conditions. For this reason, it is essential to assess the quality of the bonding. Design and control guidelines are recently available, both at national and international level $[1,2,3,4]$. Moreover, the possible presence of defects and imperfections occurred in the composite application phase or the damage due to overloading conditions, should be considered $[5,6,7,8,9,10]$. The standards currently in force recommend both the use of minordestructive, by pull-off and shear tests, and non-destructive methods, mainly based on direct inspection or waves emissions (acoustic, ultrasonic and thermal imaging are briefly mentioned). As known, the ICBO standard allows defects in the bonding if less than $13 \mathrm{~cm}^{2}$, for a maximum of 10 delaminations per $\mathrm{m}^{2}$. In the standard codes the minimum resolution required for the dimension of the smallest defects to be identified by means of NDT is indicated in $5 \mathrm{~cm}$. In general, the more advanced standards set the limit for acceptable defects, both in terms of number and size. Therefore, it is essential to use Non-Destructive Evaluation (NDE) to assess the bond quality. In 
particular, the interface between FRP and the bulk material as reinforced concrete is examined in order to characterize the perfect matching with FRP. The main aim of this work is to develop a reliable and confident NDE procedure to characterize the size of the delamination and its location.

Among others, IR thermography appears as probably the best method for NDE of civil structures strengthened by FRP $[11,12,13,14,15,16]$. Thermography is being given more and more attention because has a very high potential to check the effectiveness of strengthening and repair intervention on structural components, both in buildings and bridges. IRT allows analysing the effects induced by any discontinuity on the thermal behaviour of the material, when submitted to a heat flux. It is then possible to locate and characterize defects causing alterations of the temperature distribution of the surface. Active thermography is well in compliance with technical and economical requirements of this application.

This paper is focused on the extension characterisation in order to evaluate quantitatively the mechanics of the FRP detachment. It is well known that an effective technique for the defect sizing is the so called full-width-half-maximum (FWHM) $[17,18,19,20,21,22,23]$. This approach is simple and robust, but to meet with a practical test, temperature contrast is not always the most suitable informative parameter. In fact, the testing procedure must balance two aspects: the quality of the results (reliability, correct detection and characterisation of the delaminations) and the productivity (ratio between the scanned surface and the occurring time). This and other requirements often push toward different thermographic techniques and among them Pulse Phase Thermography (PPT) [24] plays an important role. For this reason the FWHM approach is extended to both phase and amplitude maps. Results are also compared with contrast maps and evaluated for both simulated and experimental data. The conceived experiments have been carried out testing CFRP applied on concrete. The fibres orientation, kind of the fabric, number of layers and the surface finishing have been considered, according to the most frequent practice.

\section{Characterisation of delaminations by IR thermography}

The main issues affecting the capability of thermography in sizing the delamination between FRP and bulk structure are: the depth of the defect $(z)$, its size $(d)$; the number and kind of layers; anisotropy of materials and the interference among defects or edges. In order to quantify this statement, synthetic data given by mathematical modelling are used. Finite difference method [25,26] (FDM) allows verifying $F W H M$ predictions. Pulsed thermography test has been simulated, as latterly performed on a real specimen. At first, the CFRP delamination is found out imposing a pulsed heat flux on the surface and looking for alterations of the normal distribution of the surface temperatures. Temperature difference between defected and sound areas $\left(T_{\mathrm{d}}(\mathrm{t})-T_{\mathrm{r}}\right)$, normalized contrast $\left(C_{\mathrm{n}}\right)$ given by eq. 1 and the time of maximum contrast have been computed and thought as informative parameter $[20,27]$.

$$
C^{n}=\frac{T_{d}(t)}{T_{d}^{m}}-\frac{T_{r}(t)}{T_{r}^{m}}
$$

Where $T^{m}{ }_{d}$ and $T^{m}{ }_{r}$ are the corresponding maximum temperature along time $(t)$.

Because of the uniform heating and emissivity of the surface, the following comparison of the analyzed cases is equivalent for the normalized contrast or temperature difference, at any time.

The model simulates a sample $100 \times 100 \mathrm{~mm}^{2}$ wide, containing defects of $10 \times 30$ $\mathrm{mm}^{2}$. The bulk material is concrete, $10 \mathrm{~mm}$ of thickness. A CFRP layer of $3 \mathrm{~mm}$ has been assumed, either for isotropic material or not (fibres oriented along $x$ direction). 
Delaminations between CFRP and concrete are simulated with $50 \mu \mathrm{m}$ of air gap. Finally, a $3 \mathrm{~mm}$ thick plaster layer, made of cement, is added on the front surface. A new delamination is also inserted at the interface between plaster and CFRP. Table 1 gives thermal properties of the materials used in the model.

Table 1. Thermal properties

\begin{tabular}{|l|l|c|c|}
\hline \multicolumn{1}{|c|}{ material } & \multicolumn{1}{c|}{$\begin{array}{c}\text { conductivity } \\
\left(\mathrm{W} \mathrm{m}^{-1} \mathrm{k}^{-1}\right)\end{array}$} & $\begin{array}{c}\text { Volumic Mass } \\
\left(\mathrm{kg} \mathrm{m}^{-3}\right)\end{array}$ & $\begin{array}{c}\text { Heat capacity } \\
\left(\mathrm{J} \mathrm{kg}^{-1} \mathrm{~K}^{-1}\right)\end{array}$ \\
\hline concrete (bulk) & 1 & 800 & 2400 \\
\hline air (defect) & 0.05 & 1.27 & 1006 \\
\hline CFRP & $0.8 \perp-7 / /$ & 1600 & 760 \\
\hline plaster & 0.72 & 1860 & 632 \\
\hline resin & 0.2 & 1300 & 1700 \\
\hline
\end{tabular}

\section{$2.1 \quad$ Normalized contrast analysis}

A quantitative investigation has been performed finding out the minimum defect dimension detectable using the mathematical simulation applied to many different cases of interest. Fig.1a shows the history of temperature difference, indicating the time of maximum for two defects, placed respectively at the interface between CFRP and below a resin layer, $2 \mathrm{~mm}$ thick. Fig. $1 \mathrm{~b}$ shows the space distribution of the maximum amplitude of the Normalized Contrast $\left(C_{n}{ }^{m}\right)$.

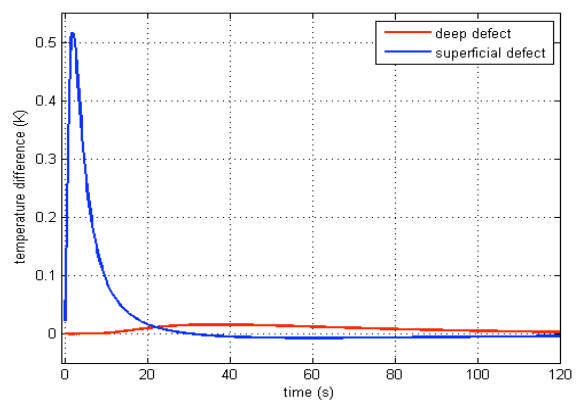

Fig. 1a. Temperature difference vs. time for the two delaminations by FDM

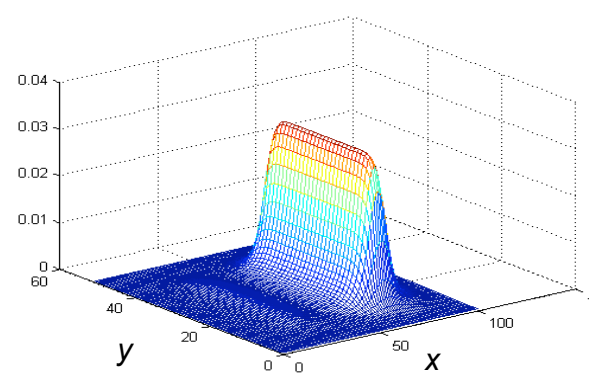

Fig. 1b. map of maximum normalized contrast in space of synthetic data

The normalized dimension $\left(d^{n}\right)$ is defined as in eq.2 and gives a parameter to classify how easy is the detection and correct sizing of the delamination. The higher $d^{n}$, the better detection and sizing will be. It was found that FWHM gives a fairly correct estimate for values of $d^{n}$ higher than about 3 , but for $d^{n}$ values, lower than 2 , a significant overestimation happens.

$$
d^{n}=\frac{d_{d}}{z_{d}} \sqrt{\frac{\alpha_{n}}{\alpha_{p}}}
$$

Where $\alpha_{n}$ is the diffusivity normal to carbon fibres and $\alpha_{p}$ that parallel to fibres. Fig.2 shows the size of the defect as estimated by the FWHM algorithm for the main analysed cases. From Fig. 2 it is understandable that the $10 \mathrm{~mm}$ width of the defect (along $x$ coordinate) is lower than the threshold for a correct evaluation using FWHM, while $30 \mathrm{~mm}$ dimension (along $y$ coordinate) is over this threshold. 


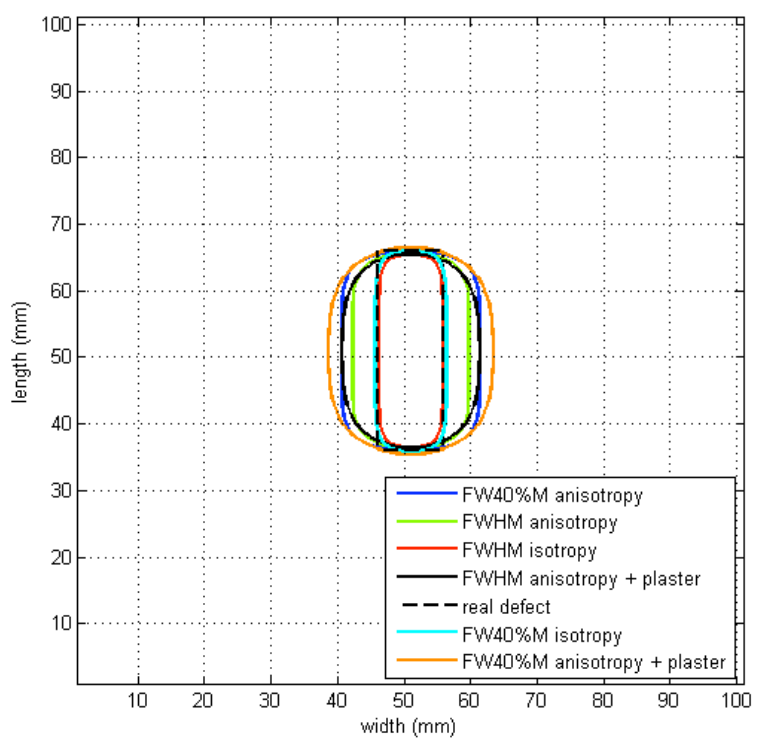

Fig2. Results of mathematical simulation on delamination sizing by FWHM or FW40\%M in different configurations of the sample (real size $10 \times 30 \mathrm{~mm}^{2}$ )

Table 2. results of simulation on delamination sizing of the sample of fig. 2 (real surface $300 \mathrm{~mm}^{2}, \alpha_{\mathrm{n}}^{0.5} \alpha_{\mathrm{p}}^{-0.5}=0.338$ )

\begin{tabular}{|l|c|c|c|c|}
\hline \multicolumn{1}{|c|}{ Analyzed cases } & $\begin{array}{c}\text { Area, } \\
\mathbf{m m}^{\mathbf{2}}\end{array}$ & $\begin{array}{c}\text { Relative } \\
\text { difference }\end{array}$ & $\boldsymbol{d ~ z}^{-1}$ & $\boldsymbol{d}^{\mathbf{n}}$ \\
\hline isotropic CFRP; FWHM & 252 & $-16 \%$ & 3.33 & 3.33 \\
\hline isotropic CFRP; FW40\%M & 306 & $+2 \%$ & 3.33 & 3.33 \\
\hline anisotropic CFRP $(x$ direction); FWHM & 455 & $+52 \%$ & 3.33 & 1.13 \\
\hline anisotropic CFRP $(x$ direction); FW40\%M & 559 & $+86 \%$ & 3.33 & 1.13 \\
\hline $\begin{array}{l}\text { anisotropic CFRP }(x) ; F W H M, \text { interacting } \\
\text { defects }\end{array}$ & 466 & $+55 \%$ & 3.33 & 1.13 \\
\hline $\begin{array}{l}\text { anisotropic CFRP }(x) ; F W H M \\
\text { + plaster 3mm }\end{array}$ & 503 & $+68 \%$ & 1.67 & 0.56 \\
\hline $\begin{array}{l}\text { anisotropic CFRP }(x) ; F W 40 \% M \\
+ \text { plaster 3mm }\end{array}$ & 636 & $+112 \%$ & 1.67 & 0.56 \\
\hline
\end{tabular}

Table 2 summarizes the resulting size, relative to the true one $\left(10 \times 30 \mathrm{~mm}^{2}\right)$. The most important cause of overestimation for our typical defects is the CFRP anisotropy (for computations: $\alpha_{p}=5.76 \times 10^{-6}\left(\mathrm{~m}^{2} \mathrm{~s}^{-1}\right.$ ) along $x$ and $\alpha_{n}=6.58 \times 10^{-7} \mathrm{~m}^{2} \mathrm{~s}^{-1}$ ). Numerical simulations indicate that delaminations over $20 \mathrm{~mm}$ placed at the interface CFRPconcrete can be correctly measured using both $50 \%$ and $40 \%$ of the maximum contrast. A distance higher than $20 \mathrm{~mm}$ is needed around each defect to avoid errors due to interference with other defects of the same kind or with the sample edges.

It has been also found that the finishing plaster layer, added on the front surface, does not affect very much the results. Vice versa, the shape of the delamination is rounded in different way and influences results, because heat flux become 3D. 


\section{$2.2 \quad$ Normalized Phase and Magnitude Analysis}

Numerical modelling is used also to verify the FWHM predictions applied to different heating functions in time. In particular the Pulse Phase Thermography (PPT) is considered attractive due to the higher probing capability and robustness of phase, if compared with amplitude based parameters [27]. This statement is validated with results of Fig. 3 showing space profiles of the normalized phase at different frequency components, computed by PPT. A large difference is found comparing Fig.3a and Fig.3c, where Fig.3c refers to exactly the same geometric model of Fig.3a, but considering the CFRP as anisotropic material. The width is systematically overestimated, because thermal properties anisotropy trims down $d^{\text {n }}$ value from 3.3 to 1.1. Furthermore, the overestimation is larger for lower frequency components ranging from $15 \%$ up to $200 \%$ ). The same is not true if comparing Fig. $3 b$ and Fig. $3 d$ where $d^{\text {n }}$ value transits from 10 to 3.4 , still over the threshold.

The most important finding does the FWHM algorithm achieve the correct sizing on the normalized phase or magnitude. Results are very little dependent on the particular frequency component chosen, if $d^{n}$ is over the same threshold of about 2 found out for the Normalized Contrast. On the contrary, for $d^{n}$ lower than 2 the higher frequency components are preferable.
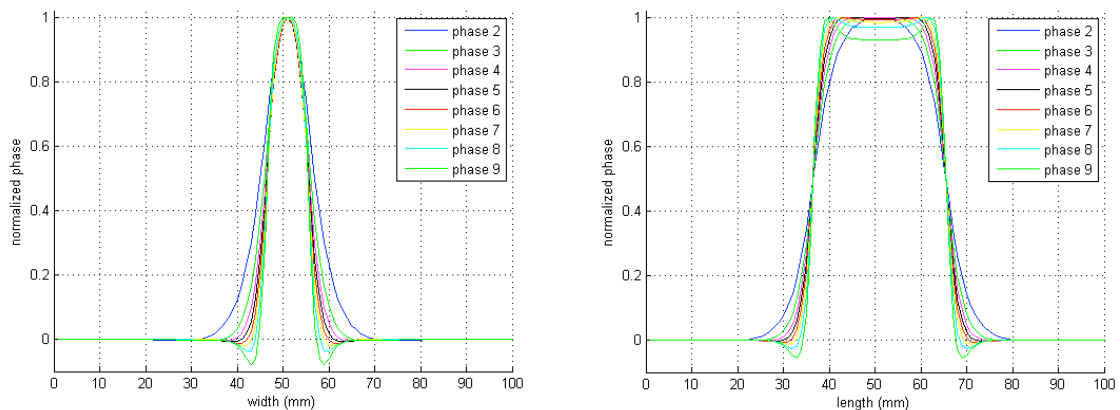

Fig. 3a. Space profile (x) of normalized Fig. 3b. Space profile (y) of normalized phase for different frequency components phase for different frequency given by PPT (delamination width $10 \mathrm{~mm}$, components given by PPT (delamination isotropic materials) length $30 \mathrm{~mm}$, isotropic materials)
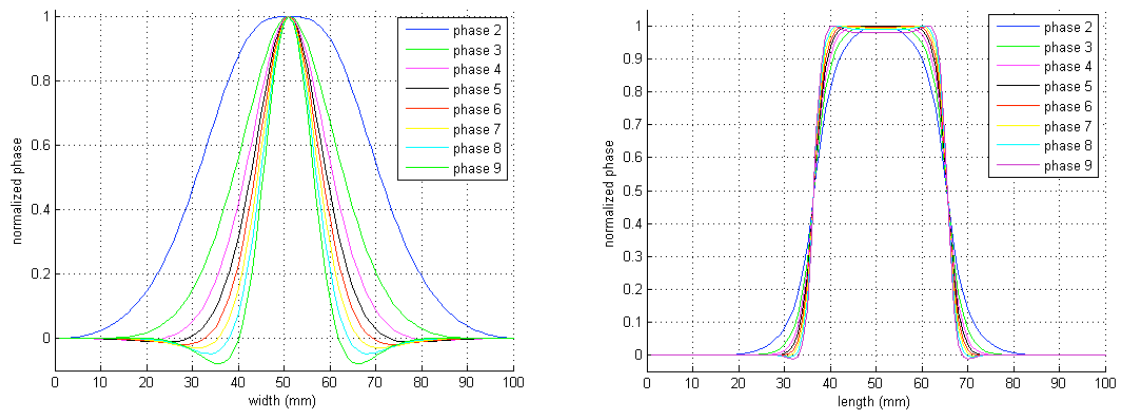

Fig. 3c. Space profile $(x)$ of normalized Fig. 3d. Space profile $(y)$ of normalized phase for different frequency components phase for different frequency given by PPT (delamination width $10 \mathrm{~mm}$, components given by PPT (delamination anisotropic CFRP) length $30 \mathrm{~mm}$, anisotropic CFRP) 
Another important conclusion is the possibility to apply the FWHM algorithm to the normalized phase given by PPT with a modulated transient heating. Fig.4 shows a computation by Finite Element Method (FEM) implemented within Femlab ${ }^{\circledR}$ using an axial symmetry (2D). The half sample simulated is $100 \mathrm{~mm}$ long and $13 \mathrm{~mm}$ thick, including a circular delamination made by air, $80 \mu \mathrm{m}$ thick and $5 \mathrm{~mm}$ wide. The defect is buried between a CFRP layer of $3 \mathrm{~mm}$ thickness and a remaining $10 \mathrm{~mm}$ thick concrete slab. Here, the imposed heat flux $(Q)$ on the front surface is modulated in time $(t)$ as follows: $Q=500\left(1-\cos \left(2 \pi f_{0} t\right)\right)$, with $f_{\mathrm{o}}=1 / 120(\mathrm{~Hz})$. Fig.4a refers to cross section of the temperature field at the end of the single heating period (120 s). Results previously obtained with the Normalized Contrast are confirmed computing the normalized temperature difference between the centre of the delamination and the sound area (the two extremes of the half-sample of Fig.4a). Fig.4b illustrates that a perfect sizing is achieved taking the $40 \%$ of the maximum (FW40\%M), at any time. This indication can be extended to the normalized phase profile computed using PPT on a single period (120 s) modulated heating, at different frequency components (see Fig. 4c). The same is also achieved using the magnitude profiles of Fig.4d, given by PPT. Of course, this conclusion could be very different dealing with noisy data.

Further simulations using finite pulse heating or modulated heating for more periods allows making valid the FWHM or FW40\%M to Normalized Contrast, Normalized Phase and Magnitudes computed by Lock In technique as well. The rules and particular weight of the above described parameters are still valid.

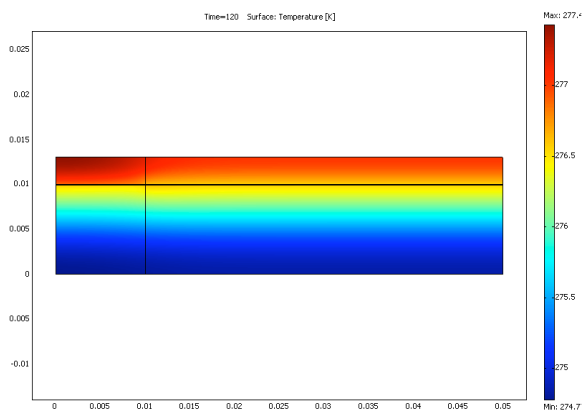

Fig. 4a. Cross section ( $t=120 \mathrm{~s}$ ) of the temperature field computed by FEM

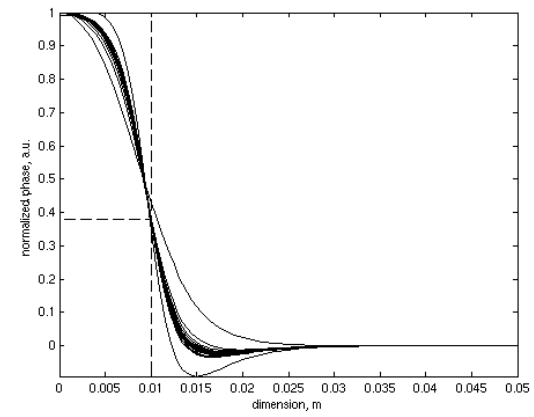

Fig. 4c. Normalized phase by PPT with a single period (120 s) modulated heating

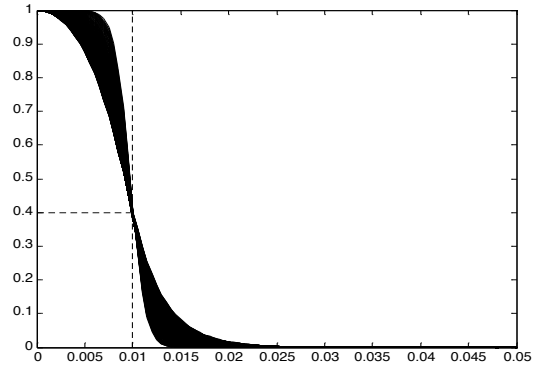

Fig.4b. Normalized surface temperature difference profiles along space at different times

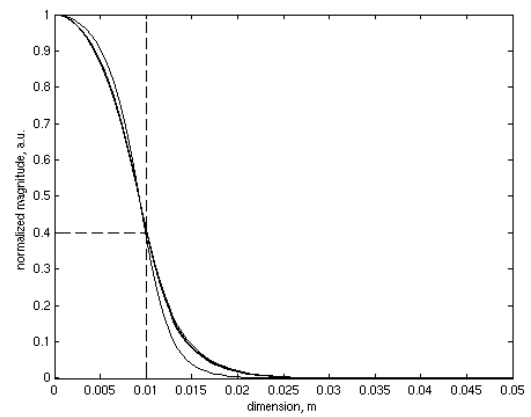

Fig. 4d. Normalized Magnitude by PPT with one modulated heating 120 s period 


\section{Experimental results}

In order to define at best the involved parameters and validate the mathematical findings a set of tests at controlled laboratory conditions have been performed on specimens manufactured in sight of mechanical tests [16]. The thermographic tests have been arranged in different ways, trying to fulfil practical conditions encountered on the inspection of the adhesion of CFRP on the substrate. The availability of a suitable heat stimulus and proper time is one of the most important issues.

A comparison of different techniques allows a first evaluation of the delamination identification and sizing. Among them, the Pulse Phase Thermography (PPT) Thermal Tomography (TT) and the Lock In Thermography (LIT) techniques have been selected, respectively as the fastest technique and more accurate one [13].

It must be stressed that the delaminations characterisation is a very challenging task. In facts, even if the discontinuities inserted in the sample have a well known size, the actual defect could be very different. For this reason, the sample has been also tested using another non-destructive method.

\subsection{Analyzed samples}

A reinforcement of concrete structures by means of CFRP has been investigated with a model prepared by specialized operators using off the shelve polymers and composites fabrics. The specimen is shown in Fig. 5 for three steps of the process for artificial defects generation. A concrete plate $\left(450 \times 450 \times 40 \mathrm{~mm}^{3}\right)$ is used as background with a cavity on its centre (marked as \#1 in Fig.5a). Artificial defects has been generated including different materials during the sample assembly: silicon grease (\#2); Teflon strips of about $50 \mu \mathrm{m}$ thickness, $10 \mathrm{~mm}$ wide and 1.5 or $3 \mathrm{~mm}$ long (\#3); Nylon squares $25 \mathrm{~mm}$ wide of about $100 \mu \mathrm{m}$ thickness (\#4). Then, the CFRP has been put in place in three bands, cured and aged, according to the manufacturer rules. Two kinds of CFRP fabric have been used: the former, with orthogonal carbon and glass fibres (centre and right bands on the picture $5 \mathrm{~b}$ ); the latter, with two layers 90 degree oriented carbon fibres (left side on the picture $5 \mathrm{~b}$ ). A primer resin has been applied at first on the supporting concrete.

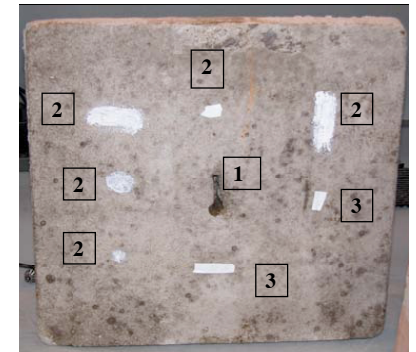

Fig. 5a. Sample setting up, concrete with different inclusions and a cavity

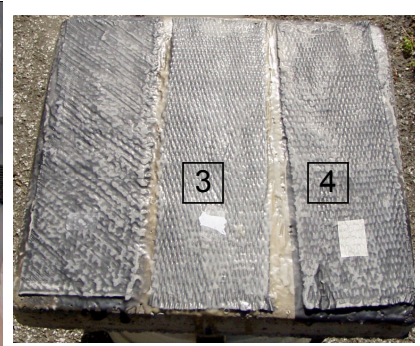

Fig. 5b. Sample with 3

CFRP bands placed on concrete and 2 inclusions

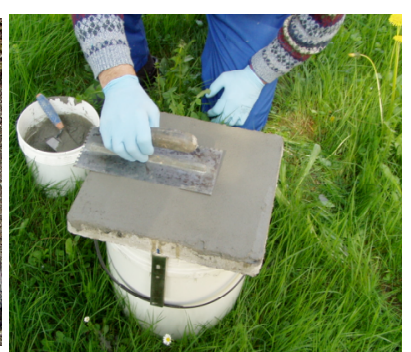

Fig. 5c. Finishing of the sample with a cement based plaster layer

At this stage, a first set of tests has been carried out using both a pulsed and modulated heating. After that, another couple of inclusions have been placed on the top of the CFRP, as shown in Fig.5b. In particular, the two Teflon inclusions placed on the centre-bottom band overlaps each other. Finally, the sample was finished with a special plaster layer of about $3 \div 5 \mathrm{~mm}$ thickness (see Fig.5c). Therefore, some very 
thin air layers are expected both at the bulk material surface and at the CFRP-plaster interface. The different inclusions thermal properties and the bad adhesion of the inserted material - resin should be detected.

Actually, it is questionable how much these artificial defects correctly represent real ones. Another problem is the real size of the delamination and their exact location. In any case, the mathematical simulations discussed before, representing the defects geometry and size helps the interpretation of the experimental results.

\subsection{Thermographic tests}

Thermography has been applied using an active approach. A pulse or periodic heat flux has been imposed on the sample surface to fire up the temperature signal. The classical experimental set up is shown in Fig. 6 , where both photographic flashes (2400 J each) and lamps (600 W each) are observable. The system used includes a thermal camera, heat sources and the digital controller.

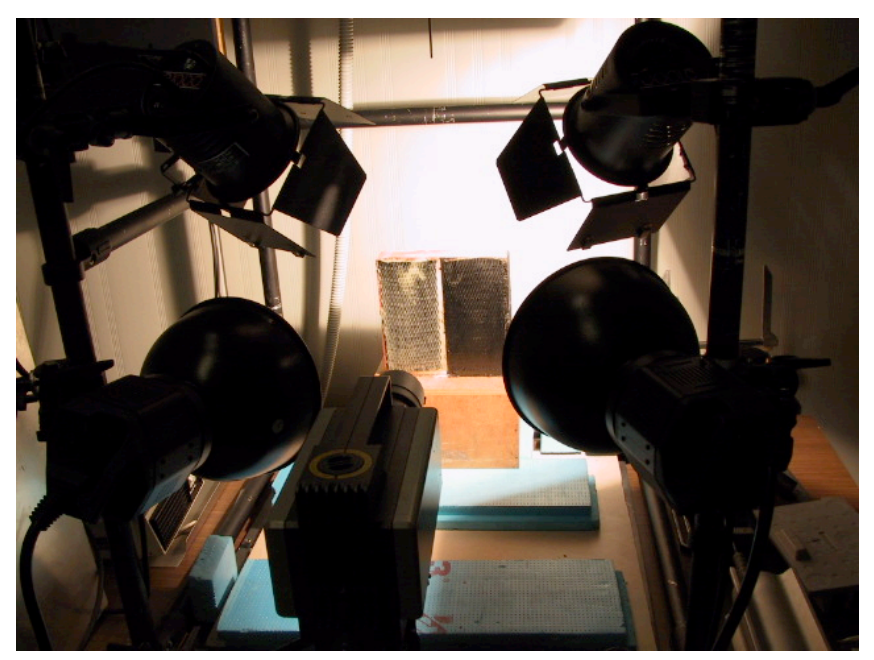

Fig. 6. Dynamic thermography set up during the heating of the sample

The whole system was synchronized and thermograms are recorded with a resolution of $320 \times 240$ pixels, 14 bit of resolution. The sequence length was about 500 images, taken at $50 \mathrm{~Hz}$ for pulsed termography or $0.25 \mathrm{~Hz}$ for modulated heating with 120 s period, which is the most suitable for this configuration. Different cameras, frame frequency and recording parameters have been applied, e.g. heating periods ranging from 5 up to $240 \mathrm{~s}$.

Temperature history of any pixel belonging to a thermographic sequence has been processed in the time and frequency domain. Defects are mapped by means of the Normalized Contrast or the space distribution of the phase angle or magnitude, given by the PPT algorithm.

It is worth noting, as PPT can efficiently unscramble different harmonic components contained in a modulated heating. This approach allows to concentrate energy around the most suitable frequency, but to scan others. Figure 7a shows the surface temperature plot vs. time for the defected areas \#8 illustrated in Fig.9a and the neighbouring one, as recorded during the test. The sample was heated with a 
single period of $120 \mathrm{~s}$ using 2 halogen lamps, modulated with a sin function by the controlling equipment (see Fig.6). Thus the transient temperature can be seen as the superposition of a step with a harmonic signal at the oscillating frequency. Fig. $7 \mathrm{~b}$ makes this clear, because the plot of magnitude vs. frequency, as computed by PPT on a thermographic sequence taken during the heating for 5 periods of 30 s has a maximum at the modulating frequency.

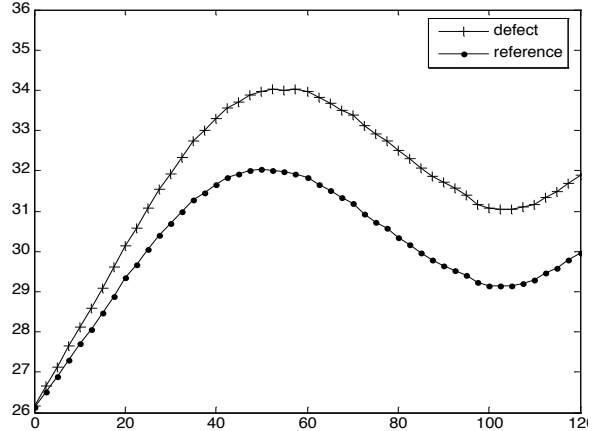

Fig. 7a. Temperature for defect \#8 and sound areas (one period heating of 120s)

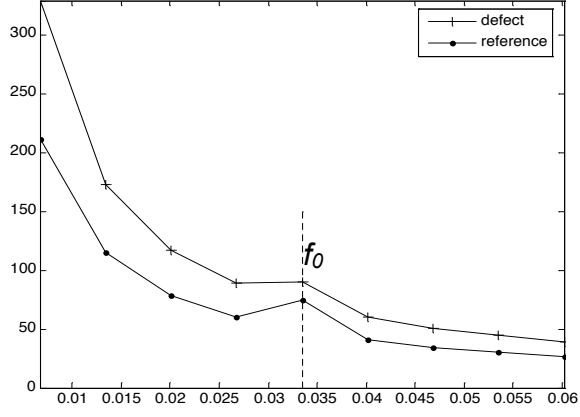

Fig. 7b. Magnitude vs. frequency by PPT (periodic heating, 5 periods of 30s)

Fig. 8 shows the results of tests performed on the sample before plastering. Fig.8a refers to the phase map, at the $2^{\text {nd }}$ frequency component given by PPT using a pulse heating and Fig. $8 \mathrm{~b}$ shows the phase map, at the $2^{\text {nd }}$ frequency component by PPT, using 10 periods of $120 \mathrm{~s}$ in transient state. From these pictures the location of discontinuities can be inferred. A very good match is found comparing Fig. 8 and Fig.5a, even if it is difficult to rank the signal with a particular material used for inclusions. Generally, the two layer CFRP used for the right band is harder to be inspected than the single layer. Some additional defects seem to be naturally born, as these marked: \#3, \#8, \#10 in fig.9a. Furthermore, the small central cavity is very well detected in any test.

After the plastering, several tests has been repeated using different procedures and data reduction algorithms. Fig.9 shows as PPT performed on a single period of $120 \mathrm{~s}$ gives excellent results. Surprisingly, the more uniform and highly emissivity surface of the plaster than CFRP compensate for the increase of the depth. Therefore, the plaster does not affect too much the detection, or in case of shine resin may be improving the test. In particular, favourable optical surface conditions allow analysing both magnitude and phase maps. Hence, considering the modulating heating of the plastered sample, for a single period of $120 \mathrm{~s}\left(f_{\mathrm{o}}=1 / 120\right)$, Fig. $9 \mathrm{a}$ is the magnitude map given by PPT at the next frequency component, while Fig $9 \mathrm{~b}$ corresponds to the magnitude at $f_{\mathrm{o}}$. The higher frequency of Fig.9b allows locating the second set of inclusions placed over CFRP whilst Fig.9a easily indicates the discontinuities below CFRP. This statement is particularly evident, looking at the discontinuity at the bottom of the central band and remembering the deeper of the two overlapping Teflon ribbons is two times longer than the shallower, as clearly shown matching Fig. 8 and 9a with 9b. 

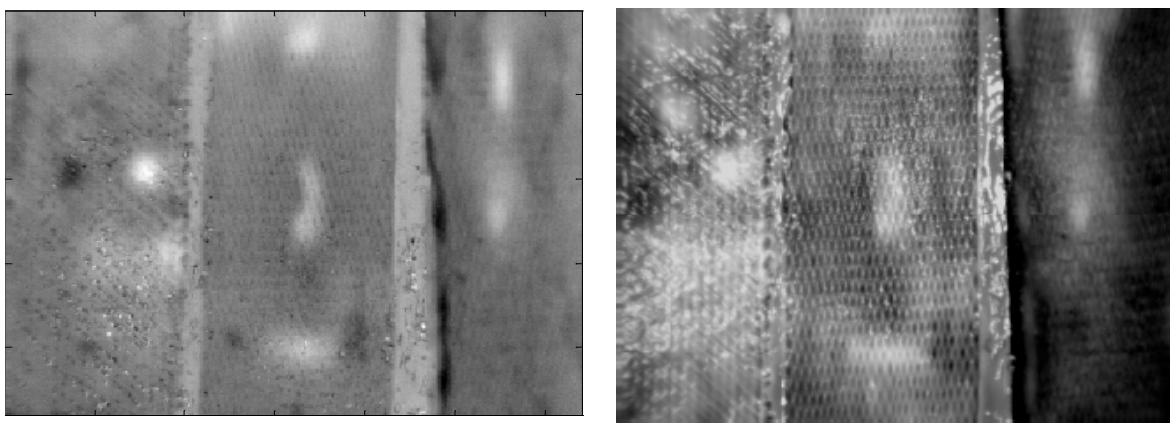

Fig. 8a. Phase map by PPT using a Fig. 8 b. Phase map by PPT, at the $2^{\text {nd }}$ pulse heating, at the $2^{\text {nd }}$ frequency frequency component using 10 periods component of $120 \mathrm{~s}$ in transient state
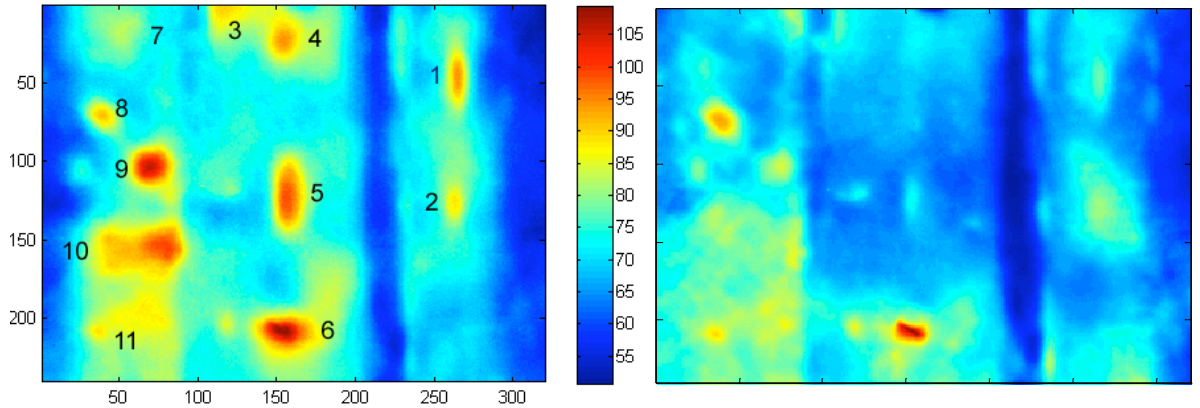

Fig. 9a. PPT magnitude map of the Fig. 9b. PPT magnitude map of the plastered sample at the next to modulating plastered sample at the modulating frequency component (single period, 120s) frequency $f_{\mathrm{o}}$ (single period, 120s)

Finally, the FW40\%M algorithm is used evaluating the size of delaminations of CFRP from concrete. The estimated areas of the deeper defects contained below CFRP within the central band of the sample are shown in Figure 10. The central picture match to the area over the $40 \%$ of the magnitude local maximum for the central band of the plastered sample, as shown at left (PPT magnitude map of Fig.9a with border lines). The right picture corresponds to the area over FW40\%M drawn on the PPT phase map of Fig.8b measured before the plastering of the sample. Quantitative results for all discontinuities are presented in table 3 and compared with results given by ultrasound $\mathrm{C}$-scan of the plastered sample. Here, it is interesting the mixture of the analysis carried out on phase or magnitude maps. Actually, in spite of the noisy results achieved before plastering, the shape of the inserts and cavity are better represented in the phase map. Nevertheless, the magnitude map of Fig.10 is much more even, allowing a simpler evaluation of the size in only one step.

The area detected by thermography is generally lower than the correspondent area measure by Ultrasounds. An error is surely related to the uncertainty about the scale factor used converting pixels into metric units. Nevertheless, signal to noise ratio is noticeably much higher on thermographic measurements than ultrasound. 

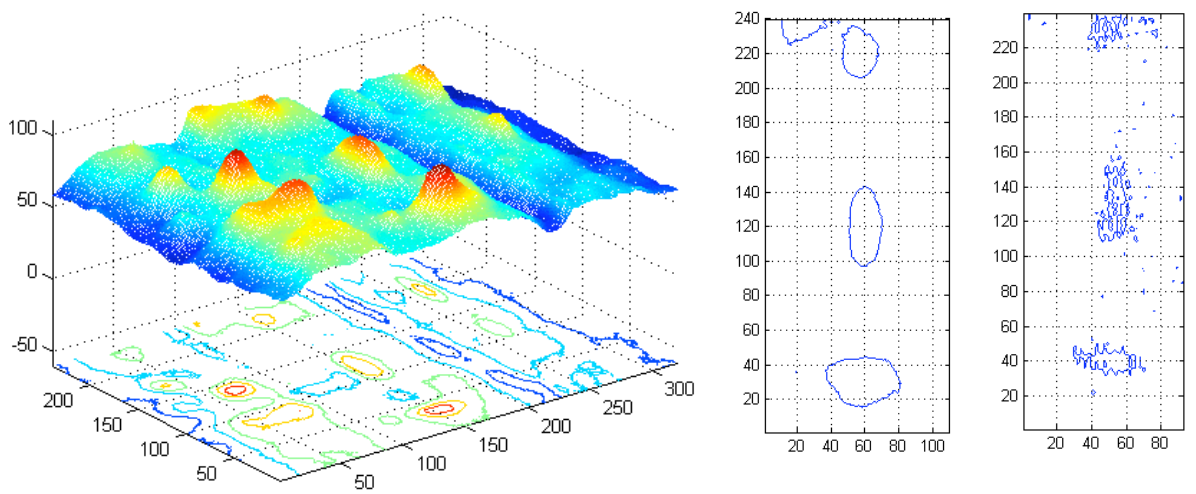

Fig. 10. Sizing of the defects contained within the plastered sample by means of FW40\%M: at left PPT magnitude map of Fig.9a with border lines, the area over the local $40 \%$ of the magnitude local maximum for the central band is shown at centre, while at right it is shown the FW40\%M of the phase (Fig.8b) for the central band of the sample without plaster

\subsection{Ultrasonic tests}

The same sample has been analysed by means of ultrasonic C-Scan inspection in pulse echo mode with a water-jet as coupling fluid. A Panametrics 9100 pulserreceiver was operated to transmit and receive ultrasonic signal. An immersion focused transducer of $10 \mathrm{MHz}$ was used for the inspection. A computer program realized with $L a b V_{i e w}{ }^{\circledR}$ permits to control the axis movement, the data acquisition and post processing images.

By means of C-Scan it is possible to obtain a two dimensional graphical presentation, in which the echoes are displayed in a top view on the test surface. The attenuation of the pulse is influenced by voids, delaminations, state of resin cure, the fibre volume fraction and any foreign inclusions present. In the presentation, reflected pulses are shown as echo exceeding a preset threshold within a gate and the drawn colour palette (or greyscale) is proportional to the amplitude of the signal.

The size measurements are achieved placing the $x$ and $y$ markers around the defected zone (see the yellow line on Fig. 11). 


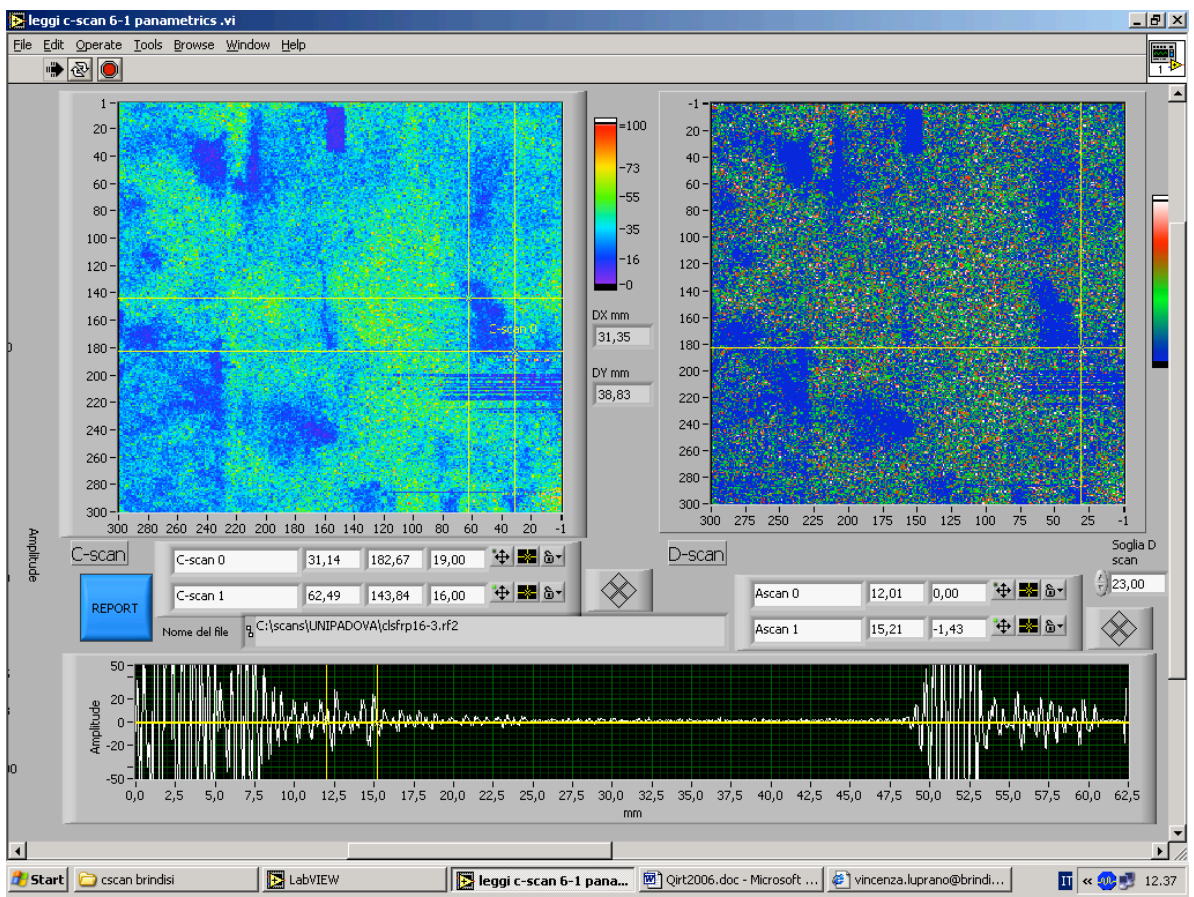

Fig. 11. Test of the plastered sample using ultrasounds C-scan

Table 3. Defects sizing by C-Scan and FW40\%M $\left[\mathrm{mm}^{2}\right]$

\begin{tabular}{|l|c|c|c|}
\hline discontinuity & $\begin{array}{c}\text { Size by US } \\
\text { after plaster }\end{array}$ & $\begin{array}{c}\text { FW40\%M } \\
\text { after plaster }\end{array}$ & $\begin{array}{c}\text { FW40\%M } \\
\text { before plaster }\end{array}$ \\
\hline$\# 1$ (grease) & $24 \times 61=1464$ & 547 & 529 \\
\hline$\# 2$ (teflon) & $31 \times 38=1178$ & 409 & 509 \\
\hline$\# 3$ (natural defect) & $10 \times 25=250$ & 300 & --- \\
\hline$\# 4$ (grease) & --- & 528 & 552 \\
\hline$\# 5$ (cavity) & $19 \times 32=608$ & 673 & 702 \\
\hline$\# 6$ (teflon) & $42 \times 27=1134$ & 813 & 435 \\
\hline$\#$ (grease) & --- & 404 & --- \\
\hline$\# 8$ (natural defect) & $10 \times 11=110$ & 310 & 119 \\
\hline$\# 9$ (grease) & --- & 378 & 196 \\
\hline$\# 10$ (natural defect) & $32 \times 66=2112$ & 1377 & --- \\
\hline$\# 11$ (grease) & --- & 824 & --- \\
\hline
\end{tabular}

\section{Conclusions}

The paper describes a suitable NDE procedure for a routinely inspection of concrete reinforced by FRP. The identification and characterization of delaminations both in depth and area are studied using mathematical modelling and experiments on a special specimen representing real conditions. The fibres orientation, fabric type and number of layers have been considered according to the most frequent practice. The influence of a plaster finishing has been investigated, as well. 
Thermographic test trimmed according to the availability of a suitable heat stimulus and proper time have been carried out. Delaminations of the FRP are found out imposing a pulsed or modulated heat flux on the surface and looking for the normalized contrast or phase and magnitude of the surface temperature.

The FWHM algorithm has been extensively explored for sizing defects placed at different depth, made including different materials and with different dimensions. Results obtained with the thermographic method applied to real and simulated sequences using different techniques shows $F W H M$ is a very simple and robust algorithm that can be successfully applied both to normalized contrast or phase maps, with similar limitations. It was found that the material anisotropy is the most relevant issue for relatively small or deep delaminations. A significant overestimation occurs for normalized dimension $\left(d^{n}\right)$ lower than 2. Furthermore, the mutual interference of defects and effects of the uneven heating are also of importance.

The detachment area estimated by thermographic techniques is compared with an ultrasound C-scan of the concrete slab supporting CFRP and covered by plaster. The surface and structural noise is now the main limiting factor for a correct sizing.

\section{REFERENCES}

[1] CEB-FIP, Externally bonded FRP reinforcement for RC structures, 2001

[2] ICBO; "Acceptance criteria for inspection and verification of concrete and reinforced and unreinforced mansory strengthening using fiber-reinforced polymer (FRP) composite systems"; ICBO Evaluation Service, INC, 05/2001

[3] $\mathrm{ACl} 440$, Guide for the design and construction of externally bonded FRP systems for strengthening concrete structures, 2002.

[4] CNR-DT 200/2005, Istruzioni per la Progettazione, l'Esecuzione ed il Controllo di Interventi di Consolidamento Statico mediante I utilizzo di Compositi Fibrorinforzati, Roma, 13 July 2004, pp.88-89

[5] Peters S.T., Handbook of Composites, Chapman \& Hall, London (UK), 1998

[6] Pesic, N., Pilakoutas, K., Concrete beams with externally bonded flexural FRP reinforcement: analytical investigation of debonding failure, Composites: Part B, 34, 2003, 327-338.

[7] Wu, Z., Yin, J., Fracturing behaviors of FRP-strengthened concrete structures, Engineering Fracture Mechanics, 70, 2003, 13391355.

[8] Yoshizawa, H., Myojo, T., Okoshi, M., Mizukoshi, M., Kliger, H.S. Effect of sheet bonding condition on concrete members having externally bonded carbon fiber sheet, $4^{\text {th }}$ Materials Engineering Conference, ASCE Annual Convention, Washington D.C., 1996.

[9] De Lorenzis, L., Miller, B., Nanni, A., Bond of FRP laminates to concrete, ACl Materials Journal, 98, 3, 2001, 256-264.

[10] De Lorentis e Nanni A., Characterization of FRP Rods as Near-Surface Mounted Reinforcement, ASCE Jouranl of Composites for Construction, vol. 5, No. 2, 2001, pp. 114-121

[11] J.G. Sun; "Analysis of quantitative measurement of defects by pulsed thermal imaging"; Review of QNDE, D.O. Thompson and D.E. Chimenti Eds., vol. 21, 2002, pp. 572-576

[12] M. A. Starnes, N. J. Carino, E. A. Kausel, "Preliminary thermography studies for quality control of concrete structures strengthened with FRP Composites", Journal of materials in civil engineering, ASCE, 2003

[13] E. Grinzato, S. Marinetti, P.G. Bison, "Controllo termografico di strutture edili fibrorinforzate" CNR ITC Padova, Conferenza Nazionale AIPnD, Milano,ottobre 2005 
[14] J.R. Brown, H.R. Hamilton III, NDE of Fiber-Reinforced Polymer Composites bonded to concrete using IR thermography, p 414-424, Spie 5405, Thermosense XXVI, 2004

[15] U. Galietti, V. Luprano, S. Nenna, L. Spagnolo, A. Tundo, "Non destructive defect characterization of concrete structures reinforced by means of FRP", AITA 8, September 2005, in press.

[16] M.R. Valluzzi, E. Grinzato, C. Pellegrino, P.G. Bison, R. Trentin, "Thermographic analysis of bond of FRP laminates applied on R.C. beams", Rilem conference, Quebec, September 2006 (in press)

[17] D.P. Almond, S.K. Lau, Defect sizing by transient thermography. I: an analytical treatment, J. Phys. D: Appl. Phys. 27, 1994.

[18] Almond, M.B. Saintey, D.P. Almond, Defect sizing by transient thermography. II: a numerical treatment, J. Phys. D: Appl. Phys. 28, 1995

[19] D.P. Almond, R. Hamzah, P. Delpech, Peng Wen, M.H. Beheshty, M. B. Saintey; "Experimental investigations of defect sizing by transient thermography"; QIRT 96-Eurotherm Series 50 ETS ed., Pisa 1997, pp.233-238

[20] J.C. Krapez, cap.13 pp. 411-439, ASNT Nondestructive Testing Handbook, third edition: Volume 3, Infrared and Thermal Testing. Technical Editor: Xavier P.V. Maldague. Editor: Patrick O. Moore, 2001

[21] D. Maillet, A.S. Houlbert, S. Didierjean, A.S. Lamine, A. Degiovanni; "Nondestructive Thermal evaluation of delaminations in a laminate: Part 1identificationby measurement of thermal contrast; Part 2-The experimental Laplace Transform Method", Composite Sciences and Technology, Vol 47, pp.137-172, Elsevier Publisher, 1993

[22] D.J. Crowther, L.D. Favro, P.K. Kuo, R.L. Thomas. Inverse scattering algorithm applied to infrared thermal wave images, J. Appl. Phys. 74 (9), 1993

[23] F. Cernuschi, Ludwig, N. Russo, A. Teruzzi P, A critical analysis and possible modifications of two analytical models for defect sizing using Video Pulse Thermography. $4^{\text {th }}$ QIRT, Eurotherm Seminar no. 60, Lodz Poland, 1998.

[24] X. Maldague and S. Marinetti, J. Appl. Phys., 79, 2694, 1996

[25] V. Vavilov, D.G. Kourtenkov, E. Grinzato, P.G. Bison, S. Marinetti, C. Bressan: "Inversion of experimental data and thermal tomography using Thermo.Heat and termidge software. "Eurotherm Seminar n. 42, QIRT 94, pp.273-278, Sorrento (Italy), 1994

[26] Muscio, S. Marinetti, P. G. Bison, A. Ciliberto, G. Cavaccini, E. Grinzato; "Modelling of Thermal Non-Destructive Evaluation Techniques for Composite Materials and the European Aerospace Industry"; AITA-Advanced Infrared Technology and Applications, Venezia, 1999, pp.143-153

[27] X.P.V. Maldague; "Theory and practice of Infrared Technology for Nondestructive Testing" John Wiley \& Sons, New York, 2001

\section{Acknowledgements}

Authors acknowledge the contribution of eng. Gianfranco Rigato from the RVM s.r.I. and eng. Gabriele Marchini from IAR s.r.l. for the materials supplying and sample manufacturing. 